\title{
O discurso indireto no alemão: um estudo quantitativo do uso dos modos ${ }^{1}$
}

\author{
Andressa Costa*
}

\begin{abstract}
This paper presents a quantitative study of the use of the Konjunktiv and Indikativ moods in German indirect speech. By analyzing a corpus of 400 news articles of online publications, it describes the factors that influence the choice of indirect speech mood. For this purpose, the following hypotheses were considered: the choice of indirect speech mood can be influenced by the type of reporting verb (sagen/to say, erklären/to explain, etc), by its position (before or after the indirect speech), by the tense of the reporting verb, by the type of verb of the indirect speech (regular, irregular, auxiliary), if the subordinate clause is initiated or not by a conjunction, the degree of embeddedness of the subordinate clause and the distance between the reporting verb and the verb of the indirect speech.
\end{abstract}

Key Words: German, Indirect Speech, Linguistic Variation, Verbal Mood

Resumo: Este artigo apresenta um estudo quantitativo do uso dos modos Konjunktiv e Indikativ no discurso indireto no alemão. Através da análise de um corpus de 400 textos online do gênero notícia de jornal, descrevem-se fatores que influenciam a escolha do modo do discurso indireto. Para a realização deste estudo partiu-se das seguintes hipóteses: a escolha do modo do discurso indireto pode ser influenciada pelo tipo de verbo do discurso citante (sagen/dizer, erklären/explicar), pela posição deste (antes ou depois do discurso citado), pelo tempo verbal do verbo finito do discurso citante, tipo de verbo do discurso citado (regular, irregular, auxiliar), se a oração subordinada é introduzida ou não por conjunção, grau de inserção da oração subordinada e distância entre discurso citante e discurso citado.

Palavras-chave: Alemão, discurso indireto; variação lingüística; ,modo verbal

\section{Introdução}

No alemão, o termo discurso indireto é comumente associado ao modo Konjunktiv que tem como uma de suas funções principais marcá-lo (Cf. DuDEN 2005:

\footnotetext{
${ }^{1}$ Artigo baseado em dissertação de mestrado defendida junto à Área de Alemão da FFLCH/USP.

* Mestre em Língua Alemã pelo Departamento de Letras Modernas da USP. E-mail: cristinnebr@yahoo.com.br
} 
Costa, A. - O discurso indireto no alemão

529; ZIFONUN et al. 1997: 1753). No Duden encontra-se a seguinte regra básica de uso do Konjunktiv na língua escrita padrão:

a) Konjunktiv I ist zu wählen, wenn die aktuelle Verbform formal eindeutig als Konjunktiv erkennbar ist. ${ }^{2}$

(1) In der Zeitung stand, die Maschinenfabrik suche noch zwei Schlosser oder Schlosserinnen. (DUDEN 2005: 541)

[No jornal estava escrito que a fábrica de máquinas procurava ainda dois serralheiros.]

Konjunktiv I - suche ( $3^{\mathrm{a}}$ pessoa singular, presente)

Indikativ - sucht ( $3^{\text {a }}$ pessoa singular presente)

b) Steht keine eindeutige Konjunktiv-I-Form zur Verfügung, erscheint der Konjunktiv II. In der 1./3. Person Plural kommt somit, außer im Fall sein, ausschließlich der Konjunktiv II infrage. ${ }^{3}$

(2) Ein Badegast drängte ans Mikrofon und fragte, warum die beiden sich nicht endlich zusammentäten. (Stern 1994)

[Um banhista correu ao microfone e perguntou por que os dois não se uniam finalmente.]

Konjunktiv II - zusammentäten ( $3^{\mathrm{a}}$ pessoa plural, Präteritum)

Indikativ und Konjunktiv I - zusammentun ( $3^{\text {a }}$ pessoa plural, presente)

No entanto, autores como EISENBERG (2004), ZiFONUN et al. (1997) e BusCHA/Zoch (1995), que se ocupam com o tema, observam que esta regra básica não é estritamente seguida no alemão atual. É cada vez mais frequente o uso do Konjunktiv II, da forma würde + Infinitiv e do Indikativ ao lado do Konjunktiv I. Por isso, esses autores tentam encontrar regularidades, a fim de descrever fatores que influenciam o uso dos modos no discurso indireto no alemão atual. Dentre os principais fatores apontados citamos: o tipo de verbo (regular, irregular, verbo sein, haben), registro linguístico, tipo de texto.

No presente trabalho foi realizado um estudo no qual se buscou descrever o uso dos modos no discurso indireto no alemão e os fatores que influenciam a escolha do modo usado, a partir da análise de um corpus. O corpus é composto por 400 textos

\footnotetext{
${ }^{2}$ Deve-se escolher o Konjunktiv I quando a forma atual do verbo é inequivocamente reconhecida como Konjunktiv.

${ }^{3}$ Caso não haja uma forma não ambígua do Konjunktiv I, então aparece o Konjunktiv II. Na $1^{\text {a }} / 3^{\mathrm{a}}$ Pessoa do plural usa-se apenas o Konjunktiv II, exceto do caso de sein.
} 
Costa, A. - O discurso indireto no alemão

online do gênero notícia de jornal, dos periódicos alemães SPIEGEL ONLINE e FAZ (Frankfurter Allgemeine Zeitung). Os dados foram analisados estatisticamente, usandose o programa SPSS for Windows (Statistical Package for the Social Sciences). Sobre o corpus, vale ressaltar que o tipo de texto usado para compô-lo (texto online) apresenta mais divergências do padrão do que o texto impresso, já que o tempo de produção e publicação do texto online é menor que o do impresso, o que pode influenciar na qualidade do texto em relação à elaboração da linguagem, mesmo que se trate de um texto do registro formal.

\section{Hipóteses}

Para o desenvolvimento da pesquisa, partiu-se das seguintes hipóteses:

1. A escolha do modo do discurso indireto pode ser influenciada pela posição do discurso citante em relação ao discurso citado, isto é, se ele está antes ou depois do discurso citado. A posição intermediária foi excluída da análise por apresentar poucos casos.

2. Um segundo fator é o tempo do verbo do discurso citante. Neste caso, quis-se verificar se há uma relação entre o tempo verbal do discurso citante e o modo do discurso citado e, em caso afirmativo, como ocorre esta relação. Em alemão falta a consecutio temporum no discurso indireto entre as orações regente e regida que há, por exemplo, no Português e Inglês. Em ambas as línguas o verbo do discurso citado passa por mudanças na forma temporal, a fim de que o seu sentido temporal se ajuste ao do verbo do discurso citante (Ver FIORIN 2002: 178-181; LEECH/SVARTVIK 1994: 132133). Em alemão, tal regra não é prevista no padrão.

3. O tipo de oração subordinada (introduzida ou não por conjunção) na qual o discurso indireto aparece também pode influenciar a escolha do modo. Como apontam Buscha/Zoch (1995: 40-42) (Veja também DudEN 2005: 538-539), o uso da conjunção torna o Konjunktiv supérfluo, já que a conjunção e o discurso citante são elementos suficientes para indicar que aquela oração é um discurso indireto e por isso o 
Costa, A. - O discurso indireto no alemão

Indikativ pode ser usado no seu lugar. No entanto, se a oração subordinada aparece sem conjunção, então o Konjunktiv é obrigatório, segundo os autores. ${ }^{4}$

4. Outro fator a ser considerado é o verbo do discurso citante. Neste caso, foi considerada, por exemplo, a questão da factividade ou não factividade do verbo do discurso citante que, segundo EISENBERG (2004: 117-118) é um aspecto que pode determinar a escolha do modo, e por isso se quis observar aqui qual é a relação verbo factivo/não factivo e Konjunktiv/Indikativ no corpus.

5. Outra hipótese é que a escolha do modo pode ser influenciada pelo tipo de verbo do discurso citado, isto é, o fato deste ser irregular, regular, misto ou um dos verbos sein (ser/estar: que é usado como auxiliar do Perfekt, passiva de estado, e como verbo pleno), haben (ter: auxiliar Perfekt, verbo pleno), werden (tornar-se: auxiliar passiva/futuro, verbo pleno) ou modal exerce algum tipo de influência na escolha do modo. Por exemplo, alguns verbos fortes possuem formas arcaicas do Konjunktiv II e por isso são substituídas com frequência pela forma würde + Infinitiv.

6. O grau de inserção ${ }^{5}$ das orações em discurso indireto pode determinar a escolha do modo. A hipótese que se levanta aqui é que quanto mais inserida for uma oração, maior a tendência a se usar Indikativ.

7. Distância dos verbos do discurso citante e do discurso citado. É provável que haja também uma relação entre a escolha do modo e a distância do discurso citante discurso citado. Isto é, quanto mais distante o verbo do discurso citado for do discurso citante, a tendência seria de aquele aparecer mais no modo Indikativ e menos no Konjunktiv.

\section{Os dados da análise}

Os dados selecionados para a análise foram restringidos às ocorrências com discurso citante anteposto ou posposto ao discurso citado, e com verbo do discurso

\footnotetext{
${ }^{4}$ Em alemão é possível sob certas condições uma oração subordinada sem conjunção com verbo finito, em Português, se a conjunção é suprimida o verbo vai para a forma infinitiva (cf. CUNHA/CINTRA 1985: $620)$.

${ }^{5} \mathrm{O}$ grau de inserção se refere ao nível de subordinação de uma oração. Oração no grau de inserção um é subordinada a uma oração principal. Uma oração no grau de inserção dois está subordinada a uma oração inserida no grau um, e assim por diante.
} 


$$
\text { Costa, A. - } \bigcirc \text { discurso indireto no alemão }
$$

citado nos modos Konjunktiv I, Konjunktiv II e Indikativ. As ocorrências com posição do discurso citante interposta e verbo no discurso citado na forma würde+Infinitiv foram excluídas por apresentarem poucos casos.

Deve-se ainda ressaltar que as ocorrências foram sempre analisadas separandose os casos com o verbo do discurso citado no singular e no plural. Com isso, quis-se evitar a influência do fator ambiguidade dos verbos que, no caso do plural, obriga o uso do Konjunktiv II em detrimento do Konjunktiv I e Indikativ por que estes dois modos apresentam muitas formas ambíguas entre si.

Acrescente-se também que houve dois momentos de análise: no primeiro momento, os dados foram analisados sem nenhum tipo de restrição; a segunda análise foi feita com restrição dos dados a determinadas ocorrências que apareceram em contextos apontados na primeira análise como favorecedor de determinado modo.

Os resultados apresentados a seguir são, portanto, desta segunda análise.

\section{Análise dos dados e resultados}

\section{Hipótese 1 - Posição do discurso citante}

Para esta análise foram utilizadas apenas ocorrências com verbo do discurso citante no Präsens ou Perfekt, pois como se observou no corpus, estes dois tempos favorecem o Indikativ cujo percentual de freqüência é bem maior do que com o verbo no Präteritum ou Plusquamperfekt. Além disso, restringiram-se os dados às ocorrências com oração subordinada no grau de inserção um por se tratar de orações subordinadas introduzidas pela conjunção dass ou sem conjunção.

As tabelas um e dois mostram o resultado da análise do corpus no que diz respeito ao uso dos modos sob a perspectiva da posição do discurso citante: 
Costa, A. - O discurso indireto no alemão

Tabela 1 - distribuição modo / posição discurso citante

Verbo do discurso citado no singular

\begin{tabular}{|l|c|c|c|}
\hline \multirow{2}{*}{ Modo } & \multicolumn{2}{|c|}{ Posição do discurso citante } & \multirow{2}{*}{ Total } \\
\cline { 2 - 3 } & anteposta & posposta & \\
\hline Konjunktiv I & 536 & 365 & 901 \\
& $93,1 \%$ & $96,6 \%$ & $94,4 \%$ \\
\hline Konjunktiv II & 17 & 7 & 24 \\
& $3 \%$ & $1,9 \%$ & $2,5 \%$ \\
\hline Indikativ & 23 & 6 & 29 \\
& $4,0 \%$ & $1,6 \%$ & $3 \%$ \\
\hline Total & 576 & 378 & 954 \\
& $100 \%$ & $100 \%$ & $100 \%$ \\
\hline
\end{tabular}

Análise estatística: Valor $5,7-\mathrm{p}=0,057^{(*)}-\mathrm{df:} 2^{6}$

Tabela 2 - distribuição modo / posição discurso citante Verbo do discurso citado no plural

\begin{tabular}{|l|c|c|c|}
\hline \multirow{2}{*}{ Modo } & \multicolumn{2}{|c|}{ Posição do discurso citante } & \multirow{2}{*}{ Total } \\
\cline { 2 - 3 } & anteposta & posposta & \\
\hline Konjunktiv I & 42 & 30 & 72 \\
& $32,6 \%$ & $29,7 \%$ & $31,3 \%$ \\
\hline Konjunktiv II & 74 & 62 & 136 \\
& $57,4 \%$ & $61,4 \%$ & $59,1 \%$ \\
\hline Indikativ & 13 & 9 & 22 \\
& $10,1 \%$ & $8,9 \%$ & $9,6 \%$ \\
\hline Total & 129 & 101 & 230 \\
& $100 \%$ & $100 \%$ & $100 \%$ \\
\hline
\end{tabular}

Análise estatística: ns - df: 2

A diferença do percentual de frequência do Konjunktiv I com discurso citante anteposto e posposto é pequena. Com as ocorrências no singular este modo é mais frequente com discurso citante posposto $(96,6 \%$ contra 93,1\%). Com as ocorrências no plural o resultado é o seguinte: $32,6 \%$ com discurso citante anteposto e $29,7 \%$ com discurso citante posposto.

\footnotetext{
${ }^{6}$ Para as variáveis de escala nominal como as frequências de tokens, foi utilizado o teste do Qui-quadrado de Pearson. Para as variáveis de escala intervalar como a distância entre os verbos do discurso citante e do discurso citado, foi usada a análise de variância com um fator (One-Way ANOVA). São apresentados três valores: a significância do valor calculado (Valor ou Valor F), o valor em si e o grau de liberdade do cálculo. Com relação ao nível de significância, um asterisco * indica que a probabilidade para um erro tipo I fica entre $1 \%$ e $5 \%(0.01 \leq \mathrm{p} \leq 0.05)$. Dois asteriscos $* *$ indicam que a probabilidade é menor que $1 \%$ $(0<\mathrm{p}<0.01)$, e três asteriscos $* * *$ que é praticamente $0 \%(\mathrm{p}=0)$. Um asterisco entre parêntese $(*)$ indica uma tendência estatística na qual a margem de erro fica entre $5 \%$ e $10 \%(0.05<\mathrm{p}<0.1)$.
} 


\section{Costa, A. - O discurso indireto no alemão}

O Konjunktiv II apresenta também resultados que se invertem conforme o verbo esteja no singular ou plural. Além disso, a diferença de percentual de sua frequência não é grande conforme o discurso citante esteja antes ou depois do citado. Desse modo, temse o seguinte resultado: o Konjunktiv II tem maior frequência nas ocorrências no singular com discurso citante anteposto (3\% contra 1,9\%) e maior frequência com discurso citante posposto nas ocorrências no plural (61,4\% contra 57,4\%).

Os resultados do Indikativ mostram uma tendência: o seu percentual de frequência é sempre maior com o discurso citante anteposto, tanto nas ocorrências no singular $(4,0 \%$ contra $1,6 \%)$ quanto nas ocorrências no plural $(10,1 \%$ contra $8,9 \%)$. Contudo, os testes estatísticos mostram que este resultado apresenta uma tendência estatística nas ocorrências com o verbo no discurso citado no singular (Valor 5,7 - p = $0,057^{(*)}-\mathrm{df}$ : dois), mas não é significativo com as ocorrências no plural.

\section{Hipótese 2 - Tempo do discurso citante}

Para a análise do uso dos modos sob a perspectiva do tempo do discurso citante, restringiram-se os dados às ocorrências com discurso citante na posição anteposta ao discurso citado e com oração subordinada com grau de inserção um.

Tabela 3 - distribuição modo / tempo do discurso citante Verbo do discurso citado no singular

\begin{tabular}{|l|c|c|c|c|c|}
\hline \multirow{2}{*}{ Modo } & \multicolumn{4}{|c|}{ Tempo do discurso citante } & \multirow{2}{*}{ Total } \\
\cline { 2 - 5 } & Präsens & Perfekt & Präteritum & Plusquamperf & \\
\hline Konjunktiv I & 82 & 14 & 473 & 63 & 632 \\
& $60,7 \%$ & $63,6 \%$ & $93,8 \%$ & $87,5 \%$ & $86,2 \%$ \\
\hline Konjunktiv II & 16 & 1 & 13 & 4 & 34 \\
& $11,9 \%$ & $4,5 \%$ & $2,6 \%$ & $5,6 \%$ & $4,6 \%$ \\
\hline Indikativ & 37 & 7 & 18 & 5 & 67 \\
& $27,4 \%$ & $31,8 \%$ & $3,6 \%$ & $6,9 \%$ & $9,1 \%$ \\
\hline Total & 135 & 22 & 504 & 72 & 733 \\
& $100 \%$ & $100 \%$ & $100 \%$ & $100 \%$ & $100 \%$ \\
\hline
\end{tabular}

Análise estatística: Valor 113,9-p=0*** - df: 6 


$$
\text { Costa, A. - } \bigcirc \text { discurso indireto no alemão }
$$

Tabela 4 - distribuição modo / tempo do discurso citante Verbo do discurso citado no plural

\begin{tabular}{|l|c|c|c|c|c|}
\hline \multirow{2}{*}{ Modo } & \multicolumn{4}{|c|}{ Tempo do discurso citante } & \multirow{2}{*}{ Total } \\
\cline { 2 - 5 } & Präsens & Perfekt & Präteritum & Plusquamperf & \\
\hline Konjunktiv I & 7 & 2 & 38 & 4 & 51 \\
& $15,6 \%$ & $66,7 \%$ & $33,9 \%$ & $23,5 \%$ & $28,8 \%$ \\
\hline \multirow{2}{*}{ Konjunktiv II } & 20 & $0 \%$ & 64 & 10 & 94 \\
& $44,4 \%$ & & $57,1 \%$ & $58,8 \%$ & $53,1 \%$ \\
\hline Indikativ & 18 & 1 & 10 & 3 & 32 \\
& $40 \%$ & $33,3 \%$ & $8,9 \%$ & $17,6 \%$ & $18,1 \%$ \\
\hline Total & 45 & 3 & 112 & 17 & 177 \\
& $100 \%$ & $100 \%$ & $100 \%$ & $100 \%$ & $100 \%$ \\
\hline
\end{tabular}

Análise estatística: Valor 25,6 - p = 0*** - df: 6

Uma observação importante sobre os quatro tempos acima é que eles são agrupados por WEINRICH (1993: 198-199) em dois registros temporais que exprimem a atitude do falante em relação à situação comunicativa atual e que indicam ao ouvinte o modo como ele deve entender aquele relato, isto é, como comentário ou narrativa. Ao grupo I pertencem os tempos do mundo comentado ${ }^{7}$ (Tempora der besprochenen Welt), a saber: Präsens, Perfekt e Futur; ao grupo II pertencem os tempos do mundo narrado (Tempora der erzählten Welt): Präteritum e Plusquamperfekt. ${ }^{8}$

O Indikativ apresenta um resultado interessante: seu percentual de frequência é sempre maior nas ocorrências nas quais o tempo do discurso citante está em um dos tempos do grupo I Präsens (27,4\% singular, 40\% plural) ou Perfekt (31,8\% singular, $33,3 \%$ plural). O Konjunktiv I apresenta também um resultado bastante interessante nas ocorrências no singular: ele é mais frequente nas ocorrências com o verbo no Präteritum (93,8\%) e no Plusquamperfekt (87,5\%), tempos do mundo narrado.

No caso do Konjunktiv II, os resultados da análise das ocorrências no singular não mostram nenhuma tendência em relação ao tempo verbal do discurso citante. Este modo teve maior percentual de frequência nas ocorrências no Präsens (11,9\%), seguido pelas ocorrências no Plusquamperfekt (5,6\%), as ocorrências no Präteritum tiveram o menor percentual $(2,6 \%)$. Já os resultados das ocorrências no plural podem ser descritas

\footnotetext{
7 Ver GouvÊA, Função dos tempos verbais no discurso. http://www.filologia.org.br/viiicnlf/anais/caderno14-09.html

${ }^{8}$ Präsens, Futur e Plusquamperfekt podem ser traduzidos como presente, futuro e mais que perfeito. Präteritum e Perfekt são formas usadas para expressar eventos passados, mas que não equivalem unilateralmente ao Pretérito imperfeito e Pretérito perfeito do Português.
} 
Costa, A. - O discurso indireto no alemão

segundo a proposta de WeINRICH (op. cit.): a frequência do Konjunktiv II é maior nas ocorrências que aparecem nos tempos do mundo narrado (Präteritum 57,1\% e Plusquamperfekt 58,5\%).

Uma explicação possível para este fato pode ser que, no singular, este modo não é tão frequente (seu percentual é de apenas 4,6\%) porque na terceira pessoa do singular, no qual todos os dados analisados se encontram, as formas verbais do Indikativ e Konjunktiv I não coincidem. No plural, todavia, este modo apresenta alta frequência de ocorrência, já que muitas vezes ele assume o papel do Konjunktiv I na marcação do discurso indireto, justamente por causa da ambiguidade de formas entre este e o Indicativo.

Como apontam os testes estatísticos, esta análise mostra resultados altamente significantes sobre o uso dos modos sob a perspectiva do tempo do discurso citante, tanto para as ocorrências no singular (Valor 113,9 - p = 0*** - df: 6) quanto para as ocorrências no plural (Valor 25,6 - p = 0*** - df: 6).

\section{Hipótese 3 - Forma da oração subordinada}

A distinção para esta análise foi feita entre oração subordinada introduzida pela conjunção dass e oração subordinada sem conjunção porque apenas esta conjunção pode ser suprimida.

Os resultados desta análise também se mostram significativos. De acordo com os testes de estatística tem-se o seguinte: Valor F 59,4 - p $=0 * * *-$ df: 2 para as ocorrências no singular e Valor F $15,1-\mathrm{p}=0,001 *$ - df: 2 para as ocorrências no plural. As tabelas cinco e seis mostram o resultado da análise. 
Costa, A. - O discurso indireto no alemão

Tabela 5 - distribuição modo / forma da subordinada

Verbo do discurso citado no singular

\begin{tabular}{|l|c|c|c|}
\hline \multirow{2}{*}{ Modo } & \multicolumn{2}{|c|}{ Tipo conector } & \multirow{2}{*}{ Total } \\
\cline { 2 - 3 } & Sem & Dass & \\
\hline Konjunktiv I & 373 & 111 & 484 \\
& $97,6 \%$ & $80,4 \%$ & $93,1 \%$ \\
\hline Konjunktiv II & 9 & 8 & 17 \\
& $2,4 \%$ & $5,8 \%$ & $3,3 \%$ \\
\hline Indikativ & $0 \%$ & 19 & 19 \\
& & $13,8 \%$ & $3,7 \%$ \\
\hline Total & 382 & 138 & 519 \\
& $100 \%$ & $100 \%$ & $100 \%$ \\
\hline
\end{tabular}

Análise estatística: Valor F 59,4 - p = 0*** - df: 2

Tabela 6 - distribuição modo / forma da subordinada Verbo do discurso citado no plural

\begin{tabular}{|l|c|c|c|}
\hline \multirow{2}{*}{ Modo } & \multicolumn{2}{|c|}{ Tipo conector } & \multirow{2}{*}{ Total } \\
\cline { 2 - 3 } & Sem & Dass & \\
\hline Konjunktiv I & 32 & 5 & 37 \\
& $38,1 \%$ & $16,1 \%$ & $32,2 \%$ \\
\hline Konjunktiv II & 49 & 18 & 67 \\
& $58,3 \%$ & $58,1 \%$ & $58,3 \%$ \\
\hline Indikativ & 3 & 8 & 1 \\
& $3,6 \%$ & $25,8 \%$ & $9,6 \%$ \\
\hline Total & 84 & 31 & 115 \\
& $100 \%$ & $100 \%$ & $100 \%$ \\
\hline
\end{tabular}

Análise estatística: Valor F $15,1-\mathrm{p}=0,001^{* *}$ - df: 2

Os resultados interessantes são do modo Indikativ e Konjunktiv I, que apresentam as seguintes regularidades: Indikativ tem maior percentual de ocorrência com as orações introduzidas pela conjunção dass (13,8\% - singular; 25,8\% - plural) e o Konjunktiv I é mais frequente nas orações sem conjunção (97,6\% - singular; 38,1\% - plural). O Konjunktiv II apresenta diferença de percentual apenas nas ocorrências no singular: seu percentual é maior nas orações com dass (5,8\%), mas nas ocorrências no plural o percentual é praticamente igual nos dois tipos de orações subordinadas $(58,3 \%$ sem conector; $58,1 \%$ com dass).

A explicação comumente apresentada nas gramáticas para este caso é que, com a conjunção, o discurso indireto já é suficientemente marcado, por isso, o Konjunktiv I é dispensável. Contudo, se falta a conjunção, então o Konjunkitv I é necessário. O 


\section{Costa, A. - O discurso indireto no alemão}

Konjunkitv II apresenta o mesmo resultado que o Indikativ. Isto é, ele tem maior frequência com as orações introduzidas pela conjunção dass.

\section{Hipótese 4 - $\mathrm{O}$ verbo do discurso citante}

Os resultados da análise sob a perspectiva do discurso citante variaram de acordo com o verbo utilizado. Foram analisados apenas os verbos com frequência mínima de oito ocorrências, com verbo do discurso citado no singular, pois o plural não teve resultados significativos (provavelmente devido à pouca quantidade de dados para cada verbo selecionado) e com oração subordinada introduzida por dass, pois só neste caso haveria ocorrências suficientes de Indikativ. Os verbos analisados foram os seguintes: glauben, berichten, sagen, begründen, erklären, betonen e hinweisen. Assim, temos o seguinte resultado:

Tabela 7 - distribuição modo / discurso citante

Verbo do discurso citado no singular

\begin{tabular}{|c|c|c|c|c|c|c|c|c|}
\hline \multirow[t]{2}{*}{ Modo } & \multicolumn{7}{|c|}{ Discurso citante } & \multirow[t]{2}{*}{ Total } \\
\hline & 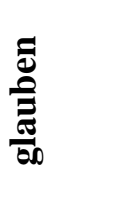 & 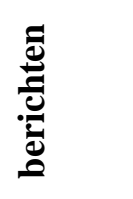 & 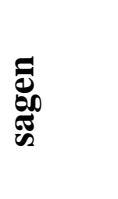 & 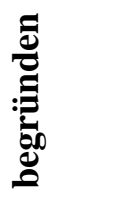 & & 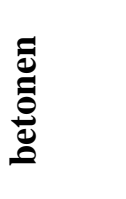 & 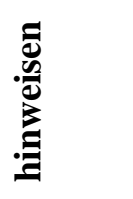 & \\
\hline Konjunktiv I & $\begin{array}{c}2 \\
25 \%\end{array}$ & $\begin{array}{c}5 \\
55,6 \%\end{array}$ & $\begin{array}{c}18 \\
75 \%\end{array}$ & $\begin{array}{c}9 \\
69,2 \%\end{array}$ & $\begin{array}{c}9 \\
64,3 \%\end{array}$ & $\begin{array}{c}8 \\
88,9 \%\end{array}$ & $\begin{array}{c}12 \\
80 \%\end{array}$ & $\begin{array}{c}63 \\
68,5 \%\end{array}$ \\
\hline Konjunktiv II & $0 \%$ & $0 \%$ & $\begin{array}{c}2 \\
8,3 \%\end{array}$ & $\begin{array}{c}2 \\
15,4 \%\end{array}$ & $\begin{array}{c}3 \\
21,4 \%\end{array}$ & $0 \%$ & $\begin{array}{c}2 \\
13,3 \%\end{array}$ & $\begin{array}{c}9 \\
9,8 \%\end{array}$ \\
\hline Indikativ & $\begin{array}{c}6 \\
75 \%\end{array}$ & $\begin{array}{c}4 \\
44,4 \%\end{array}$ & $\begin{array}{c}4 \\
16,7 \%\end{array}$ & $\begin{array}{c}2 \\
15,4 \%\end{array}$ & $\begin{array}{c}2 \\
14,3 \%\end{array}$ & $\begin{array}{c}1 \\
11,1 \%\end{array}$ & $\begin{array}{c}1 \\
6,7 \%\end{array}$ & $\begin{array}{c}20 \\
21,7 \%\end{array}$ \\
\hline Total & $\begin{array}{c}8 \\
100 \%\end{array}$ & $\begin{array}{c}9 \\
100 \%\end{array}$ & $\begin{array}{c}24 \\
100 \%\end{array}$ & $\begin{array}{c}13 \\
100 \%\end{array}$ & $\begin{array}{c}14 \\
100 \%\end{array}$ & $\begin{array}{c}9 \\
100 \%\end{array}$ & $\begin{array}{c}15 \\
100 \%\end{array}$ & $\begin{array}{c}92 \\
100 \%\end{array}$ \\
\hline
\end{tabular}

Análise estatística: Valor $24-\mathrm{p}=0,020^{*}$ - df: 12

Berichten, sagen, begründen, erklären, betonen e hinweisen apresentaram maior percentual de ocorrências com o modo Konjunktiv I.

$\mathrm{O}$ resultado mais inesperado foi do verbo glauben. Ele tem três vezes mais casos no Indikativ (75\%) do que no Konjunktiv I (25\%). Todavia, a factividade neste caso não é uma explicação, pois este verbo é não-factivo, e por isso, se esperaria mais Konjunktiv 


$$
\text { Costa, A. - } \bigcirc \text { discurso indireto no alemão }
$$

I. A explicação possível para o caso de glauben, que se pode encontrar no corpus, é que este verbo ocorre mais em contextos que favorecem o Indikativ do que em contextos nos quais o Konjunktiv I é preferido. Isto é, em todas as ocorrências em questão, glauben está anteposto ao discurso citado e em cinco das seis ocorrências com Indikativ, glauben está no Präsens e apenas em um caso ele está no Präteritum. Já nas duas ocorrências com o Konjunktiv I no discurso indireto, glauben está no Konjunktiv I. Estes dois casos podem ser justificados pelo fato de que a oração com glauben é discurso indireto como se pode notar abaixo:

(3) Die britische Polizei glaube, dass der Schlüssel für Litwinenkos Tod bei dieser Gruppe liege, berichtet der "Guardian". (SPIEGEL ONLINE Politik Ausland 186. Artikel: 01. Dezember 2006)

[A polícia britânica acredita que a chave para a morte de Litwinenko está neste grupo, informa o "Guardian".]

(4) Die CDU-geführte Landesregierung glaube offenbar, dass das Land Hessen ihr gehöre. (FAZ Politik Länder 213. Artikel: 05. Januar 2007) [O governo encabeçado pelo CDU acha aparentemente que o estado de Hesse pertence a ele.]

glaube (acreditar/achar) - $3^{\text {a }}$ Pessoa singular Konjunktiv I Präsens

Neste caso também o teste mostra um resultado significativo nas ocorrências no singular (Valor $24-\mathrm{p}=0,020 *$ - df: 12 ).

\section{Hipótese 5 - Tipo do verbo do discurso citado}

Para esta análise restringiram-se os dados às ocorrências com discurso citante anteposto, verbo do discurso citante no Präteritum ou Plusquamperfekt e oração subordinada com grau de inserção um. As colunas foram ordenadas decrescentemente de acordo com o percentual de frequência do Indikativ, por isso a ordenação não é a mesma nas tabelas no singular e plural. Assim, têm-se os seguintes resultados significativos segundo o teste estatístico (ocorrências no singular Valor F 34,9 $\mathrm{p}=0,01 *$ - df: 8; ocorrências no plural Valor F $135-\mathrm{p}=0 * * *-\mathrm{df}: 18)$. 
Costa, A. - O discurso indireto no alemão

Tabela 8 - distribuição modo / tipo do verbo

Verbo do discurso citado no singular

\begin{tabular}{|c|c|c|c|c|c|c|c|c|c|c|c|}
\hline \multirow[t]{2}{*}{ Modo } & \multicolumn{10}{|c|}{ Tipo de verbo } & \multirow[t]{2}{*}{ Total } \\
\hline & 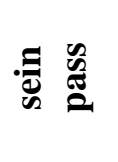 & 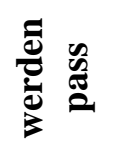 & 丞: & 营 & 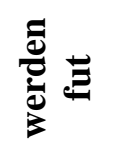 & 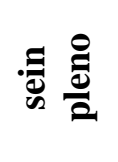 & 苋 & 离 & 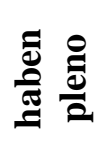 & 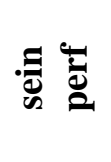 & \\
\hline Konj I & $\begin{array}{c}13 \\
86,7 \%\end{array}$ & $\begin{array}{c}19 \\
82,6 \%\end{array}$ & $\begin{array}{c}92 \\
87,6 \%\end{array}$ & $\begin{array}{c}65 \\
95,6 \%\end{array}$ & $\begin{array}{c}43 \\
95,6 \%\end{array}$ & $\begin{array}{c}70 \\
89,7 \%\end{array}$ & $\begin{array}{c}81 \\
97,6 \%\end{array}$ & $\begin{array}{c}81 \\
97,6 \%\end{array}$ & $\begin{array}{c}19 \\
100 \%\end{array}$ & $\begin{array}{c}46 \\
97,9 \%\end{array}$ & $\begin{array}{c}529 \\
93,5 \%\end{array}$ \\
\hline Konj II & $0 \%$ & $\begin{array}{c}1 \\
4,3 \%\end{array}$ & $\begin{array}{c}8 \\
7,6 \%\end{array}$ & $0 \%$ & $0 \%$ & $\begin{array}{c}5 \\
6,4 \%\end{array}$ & $0 \%$ & $\begin{array}{c}1 \\
1,2 \%\end{array}$ & $0 \%$ & $\begin{array}{c}1 \\
2,1 \%\end{array}$ & $\begin{array}{c}16 \\
2,8 \%\end{array}$ \\
\hline Ind & $\begin{array}{c}2 \\
13,3 \%\end{array}$ & $\begin{array}{c}3 \\
13 \% \\
\end{array}$ & $\begin{array}{c}5 \\
4,8 \% \\
\end{array}$ & $\begin{array}{c}3 \\
4,4 \% \\
\end{array}$ & $\begin{array}{c}2 \\
4,4 \% \\
\end{array}$ & $\begin{array}{c}3 \\
3,8 \% \\
\end{array}$ & $\begin{array}{c}2 \\
2,4 \% \\
\end{array}$ & $\begin{array}{c}1 \\
1,2 \%\end{array}$ & $0 \%$ & $0 \%$ & $\begin{array}{c}21 \\
3,7 \% \\
\end{array}$ \\
\hline Total & $\begin{array}{c}15 \\
100 \%\end{array}$ & $\begin{array}{c}23 \\
100 \%\end{array}$ & $\begin{array}{c}105 \\
100 \%\end{array}$ & $\begin{array}{c}68 \\
100 \%\end{array}$ & $\begin{array}{c}45 \\
100 \%\end{array}$ & $\begin{array}{c}78 \\
100 \%\end{array}$ & $\begin{array}{c}83 \\
100 \%\end{array}$ & $\begin{array}{c}83 \\
100 \%\end{array}$ & $\begin{array}{c}19 \\
100 \%\end{array}$ & $\begin{array}{c}47 \\
100 \%\end{array}$ & $\begin{array}{c}566 \\
100 \%\end{array}$ \\
\hline
\end{tabular}

Análise estatística: Valor F 34,9 - p = 0,01* - df: 18

Tabela 9 - distribuição modo / tipo do verbo

Verbo do discurso citado no plural

\begin{tabular}{|c|c|c|c|c|c|c|c|c|c|c|c|}
\hline \multirow[t]{2}{*}{ Modo } & \multicolumn{10}{|c|}{ Tipo de verbo } & \multirow[t]{2}{*}{ Total } \\
\hline & 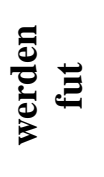 & 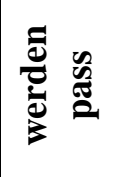 & 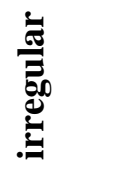 & 离 & 咅 & 宓 & 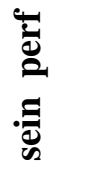 & 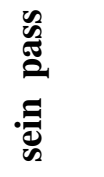 & $\begin{array}{l}\bar{D} \\
\bar{\Xi} \\
\bar{\Xi}\end{array}$ & 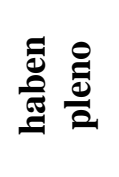 & \\
\hline Konj I & $0 \%$ & $0 \%$ & $0 \%$ & $0 \%$ & $\begin{array}{c}18 \\
85,7 \%\end{array}$ & $0 \%$ & $\begin{array}{c}17 \\
100 \%\end{array}$ & $\begin{array}{c}4 \\
100 \%\end{array}$ & $0 \%$ & $0 \%$ & $\begin{array}{c}39 \\
31,5 \%\end{array}$ \\
\hline Konj II & $0 \%$ & $\begin{array}{c}4 \\
66,7 \%\end{array}$ & $\begin{array}{c}16 \\
76,2 \%\end{array}$ & $\begin{array}{c}9 \\
81,8 \%\end{array}$ & $0 \%$ & $\begin{array}{c}23 \\
95,8 \%\end{array}$ & $0 \%$ & $0 \%$ & $\begin{array}{c}17 \\
100 \%\end{array}$ & $\begin{array}{c}2 \\
100 \%\end{array}$ & $\begin{array}{c}71 \\
57,3 \%\end{array}$ \\
\hline Ind & $\begin{array}{c}1 \\
100 \%\end{array}$ & $\begin{array}{c}2 \\
33,3 \%\end{array}$ & $\begin{array}{c}5 \\
23,8 \%\end{array}$ & $\begin{array}{c}2 \\
18,2 \%\end{array}$ & $\begin{array}{c}3 \\
14,3 \%\end{array}$ & $\begin{array}{c}1 \\
4,2 \%\end{array}$ & $0 \%$ & $0 \%$ & $0 \%$ & $0 \%$ & $\begin{array}{c}14 \\
11,3 \%\end{array}$ \\
\hline Total & $\begin{array}{c}1 \\
100 \%\end{array}$ & $\begin{array}{c}6 \\
100 \%\end{array}$ & $\begin{array}{c}21 \\
100 \%\end{array}$ & $\begin{array}{c}11 \\
100 \%\end{array}$ & $\begin{array}{c}21 \\
100 \%\end{array}$ & $\begin{array}{c}24 \\
100 \%\end{array}$ & $\begin{array}{c}17 \\
100 \%\end{array}$ & $\begin{array}{c}4 \\
100 \%\end{array}$ & $\begin{array}{c}17 \\
100 \%\end{array}$ & $\begin{array}{c}2 \\
100 \%\end{array}$ & $\begin{array}{c}124 \\
100 \%\end{array}$ \\
\hline
\end{tabular}

Análise estatística: Valor F 135 - $\mathrm{p}=0 * * *$ - df: 18

Observando os resultados, nota-se que o Indikativ apresenta maior índice de frequência com os verbos sein e werden como auxiliar da passiva nas ocorrências no singular (13,3\% e $13 \%$ respectivamente). No entanto, nas ocorrências no plural este resultado não se manteve com o verbo sein na mesma função, que não foi registrado nenhuma vez. 


$$
\text { Costa, A. - } \bigcirc \text { discurso indireto no alemão }
$$

O Konjunktiv I tem alto índice de ocorrência no singular com todos os tipos de verbos analisados, apenas nas ocorrências no plural o seu percentual de frequência restringe-se aos casos com sein (pleno (85,7\%), auxiliar do Perfekt (100\%) e da passiva (100\%)). Já que é o único verbo que tem forma não ambígua com o Indikativ, isso justifica o fato de todas as ocorrências no plural deste verbo estarem neste modo.

O Konjunktiv II predomina nas ocorrências no plural com a maioria dos verbos, à exceção de sein, fato esperado por se tratar do plural. Nas ocorrências no singular, este modo mostra maior percentual de frequência com os verbos modais $(7,6 \%)$, seguido por sein pleno $(6,4 \%)$.

\section{Hipótese 6 - Grau de inserção}

Os dados desta análise foram restringidos às ocorrências com discurso citante anteposto e verbo do discurso citante no Präteritum e Plusquamperfekt. As tabelas dez e onze apresentam os resultados da análise.

Tabela 10- distribuição modo / grau de inserção

Verbo do discurso citado no singular

\begin{tabular}{|l|c|c|c|c|}
\hline \multirow{2}{*}{ Modo } & \multicolumn{3}{|c|}{ Grau de inserção } & \multirow{2}{*}{ Total } \\
\cline { 2 - 4 } & Grau um & Grau dois & Grau três & \\
\hline \multirow{2}{*}{ Konjunktiv I } & 536 & 78 & 6 & 620 \\
& $93,1 \%$ & $79,6 \%$ & $66,7 \%$ & $90,8 \%$ \\
\hline Konjunktiv II & 17 & 2 & $0 \%$ & 19 \\
& $3 \%$ & $2 \%$ & & $2,8 \%$ \\
\hline Indikativ & 23 & 18 & 3 & 44 \\
& $4 \%$ & $18,4 \%$ & $33,3 \%$ & $6,4 \%$ \\
\hline Total & 576 & 98 & 9 & 683 \\
& $100 \%$ & $100 \%$ & $100 \%$ & $100 \%$ \\
\hline
\end{tabular}

Análise estatística: Valor 39,8 - p = 0*** - df: 4 
Costa, A. - O discurso indireto no alemão

Tabela 11 - distribuição modo / grau de inserção Verbo do discurso citado no plural

\begin{tabular}{|l|c|c|c|c|}
\hline \multirow{2}{*}{ Modo } & \multicolumn{3}{|c|}{ Grau de inserção } & \multirow{2}{*}{ Total } \\
\cline { 2 - 4 } & Grau um & Grau dois & Grau três & \\
\hline Konjunktiv I & 42 & 4 & 3 & 49 \\
& $32,6 \%$ & $16,7 \%$ & $60 \%$ & $31 \%$ \\
\hline \multirow{2}{*}{ Konjunktiv II } & 74 & 10 & 2 & 86 \\
& $57,4 \%$ & $41,7 \%$ & $40 \%$ & $54,4 \%$ \\
\hline Indikativ & 13 & 10 & $0 \%$ & 23 \\
& $10,1 \%$ & $41,7 \%$ & & $14,6 \%$ \\
\hline Total & 129 & 24 & 5 & 158 \\
& $100 \%$ & $100 \%$ & $100 \%$ & $100 \%$ \\
\hline
\end{tabular}

Análise estatística: Valor 16,3 - p =0,003** - df: 4

Os resultados mostram a seguinte tendência em relação ao modo Indikativ: ele tem o seu percentual de frequência aumentado quanto mais inserida for a oração subordinada. Isso acontece tanto com as ocorrências com o verbo no singular quanto no plural. (4\% $18,4 \%$ - 33,3\%; 10,1\% - 41,7\% - apenas o grau três no plural não apresentou ocorrências com este modo).

O Konjunktiv I apresenta um resultado progressivo descendente nas ocorrências com verbo no singular: seu percentual diminui quanto mais inserida for a oração $(93,1 \%$ - 79,6\% - 66,7\%). Já as ocorrências no plural não apresentam resultado interessante para este modo. Seu percentual é maior com as orações no grau três $(60 \%)$ seguido pelas orações no grau um $(32,6 \%)$.

O Konjunktiv II não apresenta grande diferença no percentual de frequência das ocorrências no singular, embora se note uma progressão descendente quanto ao percentual de frequência deste modo $(3 \%-2 \%-0 \%)$. O mesmo tipo de progressão pode ser percebido nas ocorrências no plural, isto é, o percentual diminui progressivamente quanto mais inserida for a oração $(57,4 \%-41,7 \%-40 \%)$.

Também se nota que as orações mais inseridas são na grande maioria relativas ou adverbiais. Já as orações em grau de inserção um são quase absolutamente orações subordinadas introduzidas por dass ou sem conjunção. O grande número de orações sem conjunção no grau de inserção um provavelmente pode ser um fator que justifique o alto índice de Konjunktiv I, já que ele é obrigatório nas orações sem conjunção. O alto índice de Indikativ nos graus dois e três pode ser justificado pela predominância de orações 
Costa, A. - O discurso indireto no alemão

adverbiais e relativas. Essas orações não permitem a supressão da conjunção, o que favorece o uso do Indikativ ou podem ser também informações adicionadas pelo autor do relato que não fazem parte do enunciado original e por isso não são discurso indireto.

Os valores $39,8-\mathrm{p}=0 * * *-\mathrm{df}: 4$ para as ocorrências no singular e $16,3-\mathrm{p}=$ $0,003 * *$ - df: 4 indicam que estes resultados são também significativos.

\section{Hipótese 7 - Distância discurso citante - discurso citado}

Aqui nos referimos à distância entre o verbo do discurso citante e o verbo do discurso citado, que foi medida contando-se o número de palavras entre os dois verbos. As restrições para esta análise são: grau de inserção um, verbo do discurso citante no Präteritum/Plusquamperfekt e discurso citante anteposto.

Tabela 12 - distribuição modo / distância Verbo do discurso citado no singular

\begin{tabular}{|l|c|c|c|}
\hline \multicolumn{1}{|c|}{ Modo } & Media & N & Desv. típ. \\
\hline Konjunktiv I & 7,1 & 536 & 6,14634 \\
\hline Konjunktiv II & 7,5 & 17 & 5,19757 \\
\hline Indikativ & 12,7391 & 23 & 5,91006 \\
\hline Total & 7,3003 & 576 & 6,20281 \\
\hline
\end{tabular}

Análise estatística: ANOVA: Valor F 9,5 - p = 0*** - df: $575(2 / 573)$

Tabela 13 - distribuição modo / distância Verbo do discurso citado no plural

\begin{tabular}{|l|c|c|c|}
\hline \multicolumn{1}{|c|}{ Modo } & Media & N & Desv. típ. \\
\hline Konjunktiv I & 7,2381 & 42 & 5,01125 \\
\hline Konjunktiv II & 7,4865 & 74 & 5,96162 \\
\hline Indikativ & 8,5385 & 13 & 5,81113 \\
\hline Total & 7,5116 & 129 & 5,62238 \\
\hline
\end{tabular}

Análise estatística: ANOVA: ns - df: 128 (2/126)

No que diz respeito à distância entre o verbo do discurso citante e o verbo do discurso citado, os resultados são bastante claros: o Indikativ é mais usado nos casos em que a distância entre ambos os verbos é maior (singular - 12,7; plural - 8,5). O Konjunktiv I é mais frequente quanto mais próximo os dois verbos estão um do outro, o que se percebe 


\section{Costa, A. - O discurso indireto no alemão}

tanto nas ocorrências no singular $(7,1)$ quanto no plural $(7,2)$. No entanto, como mostram os testes estatísticos, apenas o resultado com as ocorrências no singular (Valor F 9,5 - p =0*** - df: 575 (2/573) são significativas.

\section{Considerações finais}

O estudo sobre o uso dos modos no discurso indireto no alemão desenvolvido neste trabalho mostrou resultados bastante satisfatórios no que diz respeito às hipóteses levantadas sobre os fatores que podem influenciar o uso dos modos no discurso indireto.

A partir dos resultados obtidos podem-se descrever os seguintes fatores que favorecem o modo Indikativ: discurso citante anteposto, verbo do discurso citante num dos tempos do grupo I (Präsens ou Perfekt), oração subordinada introduzida por dass, grau de inserção dois ou três e maior distância entre o verbo do discurso citante e o verbo do discurso citado.

O Konjunktiv I teve maior percentual de frequência com os seguintes fatores: posposição do discurso citante, verbo do discurso citante num dos tempos do grupo II (Präteritum ou Plusquamperfekt) apenas nas ocorrências do singular, oração subordinada sem conector, oração no grau de inserção um e menor distância entre o verbo do discurso citante e o verbo do discurso citado.

O Konjunktiv II apresentou resultados bastante variados, dependendo se as ocorrências estivessem no singular ou plural. No entanto, puderam-se observar as seguintes tendências para o uso deste modo no corpus: nas ocorrências no plural, ele mostrou maior percentual com discurso citante posposto, verbo do discurso citante num Präteritum ou Plusquamperfekt (Tempos do grupo II), e oração subordinada sem conector. O único resultado constante tanto com as ocorrências no singular quanto no plural refere-se ao grau de inserção. Seu percentual decresce progressivamente quanto mais inserida for a oração.

Ressalte-se que este estudo limitou-se a uma análise da frequência de uso dos modos sob as perspectivas dos fatores acima expostos. Um estudo aprofundado que tenha como intuito explicar o porquê dos resultados foge ao escopo deste trabalho. Um estudo mais aprofundado do tema poderia ser feito com ocorrências restringidas a apenas um verbo do discurso citante (sagen, por exemplo, por ser o verbo introdutor de 


$$
\text { Costa, A. - } \bigcirc \text { discurso indireto no alemão }
$$

discurso prototípico em alemão), orações introduzidas por dass, verbo do discurso citante num dos tempos do grupo I (Präsens ou Perfekt), discurso citante anteposto e oração no grau de inserção um. Desse modo, se poderia analisar mais detalhadamente a interação destes fatores na influência da escolha do modo do discurso indireto.

\section{Referências bibliográficas}

AuER, Peter (1998). "Zwischen Parataxe und Hypotaxe: 'abhängige Hauptsätze' im Gesprochenen und Geschriebenen Deutsch'. in: Zeitschrift für Germanistische Linguistik 1998, 284-307.

BRAUn, Peter. Tendenzen in der deutschen Gegenwartsprache: Sprachvarietäten. 2. Aufl. Stuttgart; Berlin; Köln; Mainz: W. Kohlhammer,1987.

BuschA, Joaquim; Zoch, Irene Der Konjunktiv. 1.Aufl. Leipzig: Langenscheidt, 1995.

DUDEN Die Grammatik: unentbehrlich für richtiges Deutsch. 7.voll. neu erarb. Und erw. Aufl. Mannheim; Leipzig; Wien; Zürich, 2005.

EISENBERG, Peter Grundriss der deutschen Grammatik: Der Satz 2. überarb. und aktual. Aufl. Stuttgart/Weimar: J. B. Metzler, Band 2, 2004.

ENGEL, Ulrich Deutsche Grammatik. Heidelberg: Groos, 1988.

ENGEL, Ulrich Deutsche Grammatik. Neubearbeitung. München: Iudicium, 2004

GLÜCK, Helmut; SAUER, Wolfgang Werner Gegenwartsdeutsch. 2. überarb.und erweit. Aufl. Stuttgart; Weimar: Metzler, 1997.

GöTZE, Lutz; Hess-LÜTTICH, Ernest W. B Knaurs Grammatik der deutschen Sprache. München: Droemer Knaur., 1989.

GouvÊA, Lúcia Helena Martins. Função dos tempos verbais no discurso. In: Cadernos do CNLF, Série VIII, n ${ }^{\text {. }}$ 14, Rio de Janeiro, 23 a 27 de agosto de 2004.

http://www.filologia.org.br/viiicnlf/anais/caderno14-09.html. (18.11.2009)

WeINRICH, Harald Textgrammatik der deutschen Sprache. Mannheim; Leipzig; Wien; Zürich: Dudenverlag, 1993.

WeINRICH, Harald Tempus: besprochene und erzählte Welt. 6., neu bearb. Aufl., I. Aufl. Dieser Ausg.. München: Beck, 2001

ZIFOnUn, Gisela; HofFMAn, Ludger; STRECKER; Bruno Grammatik der deutschen Sprache. Berlin; New York: Walter de Gruyter. Band 2/Band 3, 1997. 